\title{
Introduction: shared foundations and diverse inquiries for advancing creativity and innovation research
}

\author{
Jing Zhou and Elizabeth D. Rouse
}

The field of creativity and innovation has advanced considerably, accumulating an impressive body of knowledge within a relatively short period of time (Anderson et al., 2014; Hennessey \& Amabile, 2010). Though closely related and often used interchangeably outside of academia, scholars typically define creativity as the generation of novel and useful ideas and innovation as the implementation of creative ideas (Amabile, 1988; Woodman et al., 1993). A diverse set of theoretical and methodological perspectives has fueled growth in research exploring creativity, innovation, and their intersection. At this exciting and critical juncture of the development of the creativity-innovation research field, this Handbook is designed to take stock of where the field has been and examine current trends in order to chart a promising path forward for future research.

Theoretically, the componential model (Amabile, 1988) and the interactional perspective (Woodman et al., 1993), both of which provided much theoretical guidance in the early years of research on creativity in the workplace, have continued to play a prominent role in guiding empirical studies. More recently, researchers have updated and enriched the componential model (Amabile \& Pratt, 2016) and have developed the motivational lens model to integrate theory of person-in-situation creativity research (van Knippenberg \& Hirst, 2020). Researchers have also made significant theoretical advancements (see, for example, Nijstad, Rietzschel, Baas, \& De Dreu, Chapter 2 in this volume; van Knippenberg \& Hoever, Chapter 3 in this volume) that deepen our understanding of the psychological mechanisms underlying the creativity-innovation process (that is, affective, cognitive, and motivational; see Zhou \& Shalley, 2011 for a more detailed review). Social network theories (e.g., Burt, 2004), with intellectual roots tracing to sociology, have also been extended to, or formulated specifically for, an understanding of creativity (e.g., Perry-Smith \& Shalley, 2003) and the creativity-innovation journey (Perry-Smith \& Mannucci, 2017).

Moreover, researchers have started to formulate new typologies, develop new constructs, and identify new research streams. For example, scholars have developed theory around different types of creativity (Unsworth, 2001), co-creation (Rouse, 2020), the bias against creativity (Mueller et al., 2012), creativity and ethics (Keem et al., 2018), and creativity receiving (Zhou et al., 2019). These ideas are related to various aspects and stages of the idea generation and implementation processes and 
are crucial for understanding not only how various forms of creativity come to be, but also how the process from creativity to innovation unfolds. Although the domains of micro-level creativity and macro-level innovation have often been studied in isolation, researchers have expanded our knowledge base by integrating these research streams and by linking research that centers on creativity and innovation with research on entrepreneurship, an adjacent research field (e.g., see Shalley et al., 2015).

Methodologically, the field has witnessed an increase in the use of qualitative research methods (e.g., Rouse \& Pratt, Chapter 15 in this volume). Though quantitative research methods have been used widely and have significantly advanced our understanding of creativity and innovation (e.g., Baas et al., 2008; Byron \& Khazanchi, 2012; Liu et al., 2016; Shalley \& Breidenthal, Chapter 1 in this volume; Shalley et al., 2004), qualitative methods provide unique tools for theory building and hypothesis generating, which complement quantitative methods. Together, qualitative and quantitative methods allow researchers to understand the complex, dynamic creativity-innovation process and its outcomes.

The Handbook of Research on Creativity and Innovation offers a great opportunity to showcase some of the most advanced and interesting work in the creativity and innovation field, to provide a platform for idea exchange and cross-fertilization, and to stimulate future research. Authors invited to contribute to this Handbook are leading scholars and prolific researchers who have conducted cutting-edge, interesting, and important work. Each individual chapter presents expert scholarly analysis and serves as a vital reference point for future studies.

We cluster the chapters in the Handbook of Research on Creativity and Innovation into three parts. Part I includes chapters that review foundations for conducting rigorous creativity research, elaborate on theoretical models that explain individual creativity and team creativity and innovation, and discuss the relationship between creativity and standardization. Part II presents chapters that analyze the social context for creativity and innovation, a thriving area of inquiry. The chapters cover a wide range of social contexts, revealing how macro social network structures and micro influences (from leaders, co-workers, family, and friends) shape individuals' creativity and innovation, and how engaging in creativity affects individuals' connections with others. Part III contains chapters that reveal a number of new topics that stretch the creativity and innovation field into new frontiers of discovery. Taken as a whole, the book represents the most advanced research in creativity and innovation at this time.

To facilitate readers' locating and using materials presented in this volume, in the paragraphs to follow we highlight the primary focus of each chapter, and comment on its contribution to the creativity and innovation literature. When appropriate, we also make connections among the chapters within each part, and discuss how the three parts relate to one another. 


\section{FOUNDATIONS OF CREATIVITY AND INNOVATION RESEARCH}

Part I, entitled "Foundations of Creativity and Innovation Research," consists of four chapters. In Chapter 1, Shalley and Breidenthal review and discuss how research in management and organizational studies have defined and measured creativity. The empirical source of their review is quantitative studies conducted in the past five years. On the basis of their review and appraisal of the conceptual definition of creativity including its novelty and usefulness dimensions, Shalley and Breidenthal evaluate type of studies, measurement instruments, and rating sources. They reveal conceptual issues and measurement methods about which the field has reached consensus, where divergence occurs, and where future research opportunities lie. Though their review focuses on defining and measuring creativity at the individual level of analysis, the guiding principles and thought processes on which much of their analysis is based generalizes to the group level of analysis. By highlighting old truths and new trends, Shalley and Breidenthal provide definitional and measurement foundations for conducting rigorous quantitative research.

In Chapter 2, Nijstad, Rietzschel, Baas, and De Dreu describe the dual pathway to creativity model (DPCM), evaluate its empirical support, and discuss future directions for extending and testing the model. They review two long-running research streams aimed at understanding cognitive underpinnings for creative idea generation: that creativity is a result of a random process involving remote association, or it is the outcome of a systematic search process. Whereas the former emphasizes cognitive flexibility, the latter underscores cognitive persistence. Nijstad and co-authors introduce the dual pathway for creativity model, which is an integration of the aforementioned two research traditions. Observing that most studies testing their model have been conducted in the behavioral laboratory, Nijstad and co-authors point out promising ways in which the model may be extended and tested in field studies. They also indicate the feasibility of extending their model from its original focus on the individual level of analysis to the team level.

Moving from a primary focus on individual creativity to a focus on team creativity and innovation, in Chapter 3, van Knippenberg and Hoever build on and extend van Knippenberg's (2017) comprehensive and influential review by examining research published subsequently. This examination leads to the conclusion that the team information elaboration perspective has been the dominant theory used in team creativity/innovation research. There has also been increased integration between this perspective and research into team leadership and team climate. Studies on team leadership have theorized how leaders facilitate team information elaboration, and studies on team climate have highlighted the role that climate plays in encouraging information elaboration among team members. These theoretical advancements anchored around team information elaboration for creativity/innovation open the door for van Knippenberg and Hoever to outline a number of exciting theoretical and empirical directions for researchers to pursue. Their fresh ideas regarding the discussion and debate about the degree to which the notions of team creativity and 
team innovation are meaningfully distinct are also likely to spark future conceptual and empirical work.

As the field of individual and team creativity/innovation continues to grow and generate scientific and actionable knowledge, the question of whether creativity and innovation are in conflict with standardization becomes more and more salient. In Chapter 4, Litchfield, Lee, and Gilson tackle this question. Reviewing research conducted at individual, team, or organizational level of analysis, they seek to understand the tension between creativity and standardization within each of these levels of analysis, as well as commonalities across different levels of analysis. They find that the relationship between creativity and standardization is more complex than previously assumed: under certain conditions they are adversaries, and under other conditions they are complements. The authors note that despite the importance for organizations to achieve the right balance of creativity and standardization, the literature on this topic is rather small. With an emphasis on individual and team levels of analysis, Litchfield et al. suggest possible research directions.

Taken together, the first set of four chapters (Chapters 1 to 4 ) present a number of key conceptual, methodological, and theoretical building blocks for research on individual and team creativity/innovation. Reflecting on these chapters, the methodological building blocks center around quantitative research methods. As the development of the creativity and innovation research field accelerates, studies using quantitative research methods will continue to play a significant role in knowledge creation. At the same time, qualitative research methods will also add significant value in advancing our understanding of creativity and innovation. Rouse and Pratt provide a comprehensive treatment of qualitative methods for creativity research in Chapter 15 of this volume. These first chapters also suggest an increased integration of social influences and interactions (for example, leadership and team climate; van Knippenberg \& Hoever, Chapter 3 in this volume) with cognitive, affective, and motivational underpinnings of creativity and innovation. Part II of this Handbook presents chapters highlighting the role of a wide range of social influences, interactions, and processes.

\section{THE ROLE OF SOCIAL INFLUENCES, INTERACTIONS, AND PROCESSES IN CREATIVITY AND INNOVATION}

Contemporary research on creativity and innovation has emphasized the role of the social context in shaping individual and team creativity. Part II of this Handbook, entitled "The Role of Social Influences, Interactions, and Processes in Creativity and Innovation," consists of six chapters (Chapters 5 to 10) that address various aspects of the social context. Early creativity research attempted to identify personal attributes that separate creative individuals from those who are not creative (Barron \& Harrington, 1981). By contrast, current theory recognizes the role that social influences play in fostering creativity and innovation. For example, social network scholars have revealed the significant impact of social network structures in affect- 
ing the quality of ideas generated by individuals embedded in their networks (e.g., Burt, 2004). In the first chapter in this set (Chapter 5), Burt describes the association between social networks and creativity and explains why network structure facilitates or inhibits information flow, creativity, and good ideas. He combines rich conceptual analysis with interesting sociogram illustrations of network structure. Citing evidence from field studies conducted in companies operating in the United States, Europe, and Asia, he underscores the essential role of network brokerage in creativity. In addition to his seminal work on structural holes and good ideas, Burt reviews and appraises extensions and advancements concerning social network structure and creativity. He then points out a number of promising avenues for future research.

When considering social influences, it is necessary to understand the role that leaders play in the process of creativity and innovation. The next two chapters address leadership for achieving creativity and innovation. In Chapter 6, Mainemelis, Epitropaki, and Kark provide an analysis of creative leadership. They maintain that though Selznick (1984 [1957]) coined the term decades ago, creative leadership is more important than ever. They conceptualize three ways in which leaders demonstrate creative leadership, and categorize extant empirical studies on leadership and creativity according to this conceptualization. Mainemelis and co-authors theorize that classifying creative leadership in its three types of manifestations facilitates understanding of why different contexts demand different manifestations of creative leadership. Sensitizing researchers to the context, their analysis provides guidelines for future research concerning creative leadership.

Chapter 7 continues the theme of leadership, albeit with a different focus that complements Chapter 6. Anchoring their analysis at the team level, Rietzschel, Rus, and Wisse focus on leadership behaviors for achieving effectiveness at different stages of team innovation. They emphasize the distinction between leading creativity (idea generation) and leading idea implementation, outline various team design factors (for example, a shared goal) and team interaction processes (for example, managing divergence versus convergence) essential for idea generation and implementation, and analyze leadership behaviors suitable for dealing with team work challenges at different stages of the team innovation journey. Comparing their analysis of what needs to be done in order to develop a full-range understanding of leadership behaviors for team innovation with the existing literature reveals substantial knowledge gaps. Rietzschel and co-authors conclude Chapter 7 by drawing attention to these knowledge gaps and future research opportunities.

As organizations increasingly rely on teams as the organizing unit for completing work tasks, it is beneficial to undertake a deep dive into the processes through which teams achieve creativity and innovation. In Chapter 8, Harvey and Ananth present such a deep dive. They describe an inductive investigation of how constraints influence the team creative processes. Situated in the asset management industry, their investigation builds on the notion of creative synthesis and captures the dynamic processes through which three types of constraints facilitated fund management teams' production of creative ideas. This qualitative investigation sheds light on the underlying reasons for why, paradoxically, the constraints actually exerted a positive 
impact on the interactions among team members in their collective effort to produce creative ideas. Harvey and Ananth reveal the functional, though counterintuitive, value of constraints in the team creative process, and show the utility of conducting qualitative studies for deepening our understanding of the rich context and dynamic processes of teams' creative work. Their deep dive provides impetus for future research to both extend our understanding of constraints and team creativity and use qualitative research methods in advancing our understanding. Rouse and Pratt provide a more detailed discussion on qualitative methods and creativity research in Chapter 15 of this book.

In addition to social influences from professional networks, leaders, and team members, family may also influence employees' creativity in the workplace. In Chapter 9, Madjar reviews and appraises the research stream concerning creativity-relevant influences from family. Casting family members as potential cognitive and emotional resources, Madjar's review of this literature takes stock of agreed-upon findings, inconsistent results, and topics that have not received sufficient research attention. This systematic review and appraisal demonstrates that social influence from those outside of the organization can exert substantial influence on employee creativity inside the organization; influences from family may promote or hinder employee creativity at work. Madjar concludes the chapter by providing special recommendations for future research concerning both the work-family interface and the influences of family on employee creativity.

Whereas Chapters 5 to 9 deal with effects of social influences and interactions on individual employee and team creativity, Chapter 10 examines effects of creativity on social connections at work. In this chapter, Goncalo, Katz, Vincent, Krause, and Yang point out the need to examine a broader range of consequences of creativity beyond the premise that employee creativity brings business benefits to organizations. Specifically, Goncalo and co-authors identify that engaging in creativity increases social connections. They analyze why engaging in creativity may propel employees to form social connections, and the processes through which this occurs. They also discuss when engaging in creativity combats a sense of loneliness, and when creativity results in rejection, social isolation, and increased loneliness. Overall, the authors suggest that organizations take into consideration the social connections (or lack thereof) that employees make when they engage in creativity. They also discuss a number of interesting directions for future research.

When the creativity research field emerged, much research focused on identifying individuals' traits and attributes in an attempt to understand and predict creativity. Recognizing the significant role that context plays in shaping individual creativity (e.g., Amabile, 1988) has substantially advanced the creativity research field. As our understanding of creativity broadens, encompassing the journey from creativity to innovation, and at multiple levels of analysis, the field has increasingly placed social relationships, interactions, and processes front and center. The six chapters included in Part II represent important research streams that have yielded, and will continue to deliver, productive results in this regard. Similarly, the chapters presented in Part III also hold considerable promise in stimulating future research. Whereas the set of 
chapters in Part II converge on their emphasis on social relationships and interactions in creativity and innovation, the set of chapters in Part III address diverse and stretching topics.

\section{STRETCHING HOW WE MAKE SENSE OF AND STUDY CREATIVITY AND INNOVATION}

Part III, descriptively entitled "Stretching How We Make Sense of and Study Creativity and Innovation," consists of five chapters (Chapters 11 to 15). In Chapter 11, Hargadon introduces a new construct called creative spirals. This construct captures an interesting phenomenon with regard to the generation of a series of creative ideas. Understanding this phenomenon requires researchers to uncover how contexts enable creative spirals to materialize. While the chapters in Part II of this volume focus on the social context for creativity and innovation, Hargadon takes a systems view and brings the sociomaterial context and temporal conditions to the fore. Using a microhistorical lens, he describes creative spirals in context, analyzing how sociomateriality and temporality shape the discovery of solutions to existing problems and the emergence of new questions. Hargadon concludes the chapter by detailing opportunities for future theoretical development, empirical research, and methodological innovation: the use of microhistorical methods to study creative spirals in sociomaterial and temporal contexts.

Whereas Hargadon centers his discussion on the meso level of analysis (for example, how the Edison lab as a collective produced creative spirals), Mannucci in Chapter 12 primarily addresses the creativity trajectory over the course of an individual's career. He reviews and appraises research on not only how creativity trajectories vary, but also why variations transpire. From person, product, and process perspectives, he analyzes factors that result in different trajectories. He also discusses factors that are beneficial to creativity at various career stages. Following the comprehensive and thoughtful review, Mannucci reveals a number of interesting future research directions.

Chapter 13 focuses on the bias against novelty. Though much research effort has been devoted to an understanding of how to increase employees' knowledge, skills, and motivation in order to boost their creativity, less research has been conducted on what happens after creative ideas have been generated and how ideas are received by others. In this chapter, Mueller and Yin highlight the challenge that ideas generators and organizations attempting to benefit from the creativity exhibited by their employees face: there is a profound bias against novelty that can translate into a bias against creativity. Mueller and Yin review this emergent literature and point out the importance of furthering this line of inquiry. They present two approaches to studying the bias against novelty, categorize existing work accordingly, and discuss future research opportunities in the emergent area of studying creativity evaluation.

Continuing a theme around creativity evaluation, Unsworth and Luksyte wonder whether idea evaluators truly evaluate creative ideas along the novelty and usefulness 
dimensions. In Chapter 14, they ask a provocative and important question: Does it matter who the creator is? They point out that the characteristics of the creator are likely to influence observers' evaluation of the ideas generated by the creator. They theorize the psychological drivers that direct the evaluator's attention toward the idea creator, instead of the idea itself. Among the characteristics of the creator, Unsworth and Luksyte identify two characteristics - age and gender - and analyze how they may influence the observers' evaluation of the idea. Given the statistics regarding workforce composition, understanding how these two characteristics affect observers' creativity evaluation is crucial for both research and management practice. Using these two characteristics to illustrate their theorizing, Unsworth and Luksyte integrate the emergent creativity evaluation literature with several extant research streams, such as the theoretical work unpacking types of creativity (Unsworth, 2001). Their theoretical analysis and integration with earlier work opens the door for quite a few interesting avenues for future research.

Chapters 1 through 14 focus on various theoretical perspectives and diverse research streams in the broad creativity and innovation arena, reviewing a wealth of knowledge created, and identifying ample research opportunities to be pursued. Chapter 15 serves as a conclusion to this volume and a call for action. In this chapter, Rouse and Pratt emphasize the need for radical theory building in research on creativity and innovation, echoing the concern that convergence may stagnate development of the field, and emphasize the value of injecting greater divergence in research questions asked, theoretical perspectives taken, and research methods used. They explain why qualitative methods are helpful in this regard, detail types of qualitative methods, and offer three shifts of focus that may especially benefit from using qualitative methods.

\section{INTENDED READERSHIP}

A variety of readers will find the book interesting and useful. PhD students and other aspiring researchers may use the book as a major reference source that helps them to become acquainted with the creativity and innovation research field. If you are a $\mathrm{PhD}$ student or an aspiring researcher, here is our suggestion: whether or not you have already chosen creativity and innovation as your area of specialization, you are likely to enjoy studying the book in the order in which we present the chapters. Approaching the material in this sequence will enable you to both acquire knowledge accumulated by the creativity and innovation research field and generate ideas for your own research. More specifically, going through the book in this sequence will facilitate your thinking about how to identify a research question that is interesting and important, generate your own research ideas, develop a theoretical model, and design an empirical study, taking either a quantitative or qualitative approach.

Experienced researchers who already specialize in the creativity and innovation research arena are likely to discover fresh ideas and thought-provoking analysis in these pages. If you are an experienced researcher, you may find it beneficial to jump 
to the chapters that intrigue you, irrespective of how we have organized the chapters. Researchers whose primary field is not creativity and innovation are likely to find the chapters interesting and useful. Getting a sense of the rapid development of the creativity and innovation field, as evident in the ideas elaborated in the chapters, is likely to stimulate the generation of fresh ideas for your research programs beyond creativity and innovation.

Finally, practicing managers and employees who are interested in understanding creativity and innovation are also likely to find the book useful. If you have already had experience in leading or engaging in idea generation, selection, and implementation, reading the chapters in this volume will help you to reflect, make sense of your own experiences, as well as plan and execute future creativity and innovation more effectively and efficiently. If you do not have much experience in creativity and innovation, thumbing through the pages of this volume will help you to appreciate the complexity and joy of the creativity-innovation journey, and seize future opportunities to engage in creativity and innovation.

\section{REFERENCES}

Amabile, T.M. 1988. A model of creativity and innovation in organizations. Research in Organizational Behavior, 10: 123-167. Greenwich, CT: JAI Press.

Amabile, T.M., \& Pratt, M.G. 2016. The dynamic componential model of creativity and innovation in organizations: Making progress, making meaning. Research in Organizational Behavior, 36: 157-183.

Anderson, N., Potocnik, K., \& Zhou, J. 2014. Innovation and creativity in organizations: A state-of-the-science review, prospective commentary, and guiding framework. Journal of Management, 40, 1297-1333.

Baas, M., De Dreu, C.K.W., \& Nijstad, B.A. 2008. A meta-analysis of 25 years of moodcreativity research: Hedonic tone, activation, or regulatory focus? Psychological Bulletin, 134: 779-806.

Barron, F., \& Harrington, D.M. 1981. Creativity, intelligence, and personality. Annual Review of Psychology, 32: 439-476.

Burt, R.S. 2004. Structural holes and good ideas. American Journal of Sociology, 110: 349-399.

Byron, K., \& Khazanchi, S. 2012. Rewards and creative performance: A meta-analytic test of theoretically derived hypotheses. Psychological Bulletin, 138: 809-830.

Hennessey, B.A., \& Amabile, T.M. 2010. Creativity. Annual Review of Psychology, 61: $569-598$.

Keem, S., Shalley, C.E., Kim, E. \& Jeong, I. 2018. Are creative individuals bad apples? A dual pathway model of unethical behavior. Journal of Applied Psychology, 103: 416-431.

Liu, D., Jiang, K., Shalley, C.E., Keem, S., \& Zhou, J. 2016. Motivational mechanisms of employee creativity: A meta-analytic examination and theoretical extension of the creativity literature. Organizational Behavior and Human Decision Processes, 137: 236-263.

Mueller, J.S., Melwani, S., \& Goncalo, J.A. 2012. The bias against creativity: Why people desire but reject creative ideas. Psychological Science, 23: 13-17.

Perry-Smith, J., \& Mannucci, P.V. 2017. From creativity to innovation: The social network drivers of the four phases of the idea journey. Academy of Management Review, 42: 53-79.

Perry-Smith, J., \& Shalley, C.E. 2003. The social side of creativity: A static and dynamic social network perspective. Academy of Management Review, 28: 89-106. 
Rouse, E.D. 2020. Where you end and I begin: Understanding intimate co-creation. Academy of Management Review, 45: 181-204.

Selznick, P. 1984 [1957]. Leadership in administration. Berkeley, CA: University of California Press.

Shalley, C.E., Hitt, M.A., \& Zhou, J. (eds). 2015. The Oxford handbook of creativity, innovation, and entrepreneurship. New York: Oxford University Press.

Shalley, C.E., Zhou, J., \& Oldham, G.R. 2004. The effects of personal and contextual characteristics on creativity: Where should we go from here? Journal of Management, 30: 933-958.

Unsworth, K.L. 2001. Unpacking creativity. Academy of Management Review, 26: 289-297. van Knippenberg, D. 2017. Team innovation. Annual Review of Organizational Psychology and Organizational Behavior, 4: 211-233.

van Knippenberg, D., \& Hirst, G. 2020. A motivational lens model of person X situation interactions in employee creativity. Journal of Applied Psychology, 105: 1129-1144.

Woodman, R.W., Sawyer, J.E., \& Griffin, R.W. 1993. Toward a theory of organizational creativity. Academy of Management Review, 18: 293-321.

Zhou, J., \& Shalley, C.E. 2011. Deepening our understanding of creativity in the workplace: A review of different approaches to creativity research. In S. Zedeck, et al. (eds), $\boldsymbol{A P \boldsymbol { A }}$ handbook of industrial and organizational psychology, Vol. 1: 275-302. Washington, DC: American Psychological Association.

Zhou, J., Wang, X., Bavato, D., Tasselli, S., \& Wu, J. 2019. Understanding the receiving side of creativity: A multidisciplinary review and implications for management research. Journal of Management, 45: 2570-2595. 